\title{
Optimizing Seeding and Culture Methods to Engineer Smooth Muscle Tissue on Biodegradable Polymer Matrices
}

\author{
Byung-Soo Kim, ${ }^{1}$ Andrew J . Putnam, ${ }^{1}$ Thomas J . Kulik, ${ }^{2}$ \\ David J . Mooney ${ }^{1,3}$ \\ ${ }^{1}$ Department of Chemical Engineering, ${ }^{2}$ Department of Pediatrics, \\ ${ }^{3}$ Department of Biologic and Materials Sciences, University of Michigan, \\ Ann Arbor Michigan 48109-2136, e-mail: mooneyd@engin.umich.edu
}

Received 24 J anuary 1997; accepted 10 J une 1997

\begin{abstract}
The engineering of functional smooth muscle (SM) tissue is critical if one hopes to successfully replace the large number of tissues containing an SM component with engineered equivalents. This study reports on the effects of SM cell (SMC) seeding and culture conditions on the cellularity and composition of SM tissues engineered using biodegradable matrices $(5 \times 5 \mathrm{~mm}, 2$ $\mathrm{mm}$ thick) of polyglycolic acid (PGA) fibers. Cells were seeded by injecting a cell suspension into polymer matrices in tissue culture dishes (static seeding), by stirring polymer matrices and a cell suspension in spinner flasks (stirred seeding), or by agitating polymer matrices and a cell suspension in tubes with an orbital shaker (agitated seeding). The density of SMCs adherent to these matrices was a function of cell concentration in the seeding solution, but under all conditions a larger number (approximately 1 order of magnitude) and more uniform distribution of SMCs adherent to the matrices were obtained with dynamic versus static seeding methods. The dynamic seeding methods, as compared to the static method, also ultimately resulted in new tissues that had a higher cellularity, more uniform cell distribution, and greater elastin deposition. The effects of culture conditions were next studied by culturing cell-polymer constructs in a stirred bioreactor versus static culture conditions. The stirred culture of SMC-seeded polymer matrices resulted in tissues with a cell density of $6.4 \pm 0.8 \times 10^{8}$ cells $/ \mathrm{cm}^{3}$ after 5 weeks, compared to $2.0 \pm 1.1 \times 10^{8}$ cells/ $\mathrm{cm}^{3}$ with static culture. The elastin and collagen synthesis rates and deposition within the engineered tissues were also increased by culture in the bioreactors. The elastin content after 5-week culture in the stirred bioreactor was $24 \pm 3 \%$, and both the elastin content and the cellularity of these tissues are comparable to those of native SM tissue. New tissues were also created in vivo when dynamically seeded polymer matrices were implanted in rats for various times. In summary, the system defined by these studies shows promise for engineering a tissue comparable in many respects to native SM. This engineered tissue may find clinical applications and provide a tool to study molecular mechanisms in vascular development. (c) 1998 J ohn Wiley \& Sons, Inc. Biotechnol Bioeng 57: 46-54, 1998.
\end{abstract}

Correspondence to: David Mooney

Contract grant sponsor: NSF

Contract grant number: BES-9501376
Keywords: smooth muscle; polyglycolic acid; biodegradable; tissue engineering

\section{INTRODUCTION}

Smooth muscle (SM) is a functionally critical component of a variety of cardiovascular, gastrointestinal, and urinary tissues (e.g., blood vessels, intestines, and bladder). Millions of patients suffer from diseases related to deficiencies of these tissues (Langer and Vacanti, 1993). These diseases are treated by organ or tissue transplantation or the use of synthetic prosthetic devices. However, organ or tissue transplantation is limited by a shortage of donor tissue suitable for transplantation, and synthetic prostheses rarely replace the entire function of the original tissue and often cause complications such as infection, calcification, and thrombus formation (Greisler, 1991; Holmes and Kirby, 1993).

The field of tissue engineering has emerged as a promising approach to treat these types of diseases without the limitations of current therapies. In this approach, cells are often isolated from a small biopsy and expanded in vitro to generate a large cell mass. These cells are then seeded onto a suitable matrix and either allowed to develop into a new tissue in vitro, or transplanted into a patient to create a new tissue that is structurally integrated with the body and replaces the functions of the lost or deficient tissue (Langer and Vacanti, 1993). Synthetic extracellular matrices (ECMs) can be used to localize cells in vitro or in vivo, define a potential space for tissue development, and guide new tissue formation from seeded cells and surrounding host cells (Langer and Vacanti, 1993; Putnam and Mooney, 1996). In the ideal situation, cells from a small biopsy are expanded in vitro to engineer a large new autologous tissue or used to treat numerous patients.

Any attempt to engineer the tissues mentioned above must include the development of functional SM. The majority of past work in this area has utilized naturally derived matrices to engineer the new SM tissue. Elastin matrices prepared directly from blood vessels were utilized in early studies (Leung et al., 1976), but more recent work has fo- 
cused on matrices fabricated from type I collagen (Dickinson et al., 1994; Hirai and Matsuda, 1995; Weinberg and Bell, 1986; Ziegler and Nerem, 1994). Weinberg and Bell (1986) first attempted to construct a blood vessel model in vitro using collagen and vascular cells. They lined endothelial cells on a collagen lattice containing SM cells (SMCs). Ziegler and Nerem (1994) engineered SM tissue by culture of SMCs within a collagen gel in order to investigate factors regulating vascular biology. Hirai and Matsuda (1995) engineered vascular tissue composed of vascular cells cultured in a collagen gel. Dickinson et al. (1994) used collagen gels to culture fibroblasts and recently expanded this system to engineer SM tissue. However, naturally derived materials such as collagen and elastin must be isolated from human, animal, or plant tissue and this typically results in a high cost and large batch to batch variations. These materials also exhibit a limited range of physical properties, and immune response to animal-derived materials is always a concern. In addition, past studies utilizing naturally derived materials were only able to achieve relatively low SMC densities $\left(10^{7}\right.$ cell $/ \mathrm{cm}^{3}$ ), which were an order of magnitude less than that found in SM tissues in vivo (Ziegler and Nerem, 1994).

Recently, we have been developing matrices fabricated from synthetic, biodegradable polymers for engineering SM tissue. Synthetic polymer matrices can be fabricated reproducibly with desired mechanical properties, degradation rates, and shapes (Gilding, 1981). Degradation of the polymer matrix following tissue development yields a totally natural tissue with no permanent foreign material. We demonstrated that SMCs and endothelial cells can be seeded onto synthetic polymer matrices to form tubular tissues in vitro with an appropriate cell distribution (Mooney et al., 1996). New urological structures for genitourinary reconstruction were also created in vivo from urothelial cells and bladder SMCs implanted on biodegradable polymer matrices (Atala et al., 1993). However, no quantitative analysis of the new tissues was attempted in these studies, nor was there any attempt to optimize the cell seeding or subsequent cellmatrix culture conditions. In this research we studied the role of cell seeding and culture methods in an attempt to optimize these variables. Strikingly, we found that these variables are not only important in terms of efficient development of a tissue, but are also critical determinants of the consistency and structure of the engineered tissue.

\section{MATERIALS AND METHODS}

\section{SMC Isolation and Culture}

SMCs were isolated and cultured using a modification of the techniques described in Rothman et al. (1992). The descending aortas of 300-350 g adult male Lewis rats (Charles River Laboratories, Wilmington, MA) were dissected free and excised. In a sterile environment, the fat, adventitia, and connective tissue surrounding the arteries were removed by blunt dissection. After a longitudinal cut to open the artery, the tissue was cut into multiple small pieces and placed into a spinner flask (100 mL, Bellco Glass Inc., Vineland, NJ) containing an enzymatic dissociation buffer at $37^{\circ} \mathrm{C}$. This buffer contains $0.125 \mathrm{mg} / \mathrm{mL}$ elastase (Sigma Chemical Co., St. Louis, MO), $1.0 \mathrm{mg} / \mathrm{mL}$ collagenase (CLS type I, 204 U/mg, Worthington Biochemical Corp., Freehold, NJ), $0.250 \mathrm{mg} / \mathrm{mL}$ soybean trypsin inhibitor (type 1-S, Sigma), and $2.0 \mathrm{mg} / \mathrm{mL}$ crystallized bovine serum albumin (BSA, Gibco/Life Technologies, Gaithersburg, MD). The tissue suspension was incubated in a spinner flask for $90 \mathrm{~min}$. After 90 min the suspension was filtered through a $100-\mu \mathrm{m}$ Nitex filter (Tetko, Inc., Briarcliff Manor, NY) and centrifuged at $200 \mathrm{~g}$ for $5 \mathrm{~min}$. The pellet was resuspended in Medium 199 (Sigma) supplemented with 20\% (v/v) fetal bovine serum (FBS, Gibco), $2 \mathrm{~m} M$ L-glutamine (Gibco), and $50 \mathrm{U} / \mathrm{mL}$ penicillin-streptomycin (Gibco). The cells were cultured in $\mathrm{T}$ flasks $\left(75 \mathrm{~cm}^{2}\right.$, Corning Inc., Corning, $\mathrm{NY}$ ) in a humidified $5 \% \mathrm{CO}_{2}$ atmosphere and the medium was changed every other day. SMCs were maintained in growth media containing $20 \%$ (v/v) FBS until the first passage. Subsequent cultures were supplemented with $10 \%$ (v/ v) FBS. Cells between passages 4 and 10 were used in all experiments.

\section{Polymer Matrices}

Polyglycolic acid (PGA) fibers (approximately $12 \mu \mathrm{m}$ in diameter) assembled into nonwoven arrays (2-mm thick) were purchased from Albany Int. (Taunton, MA). The bulk density of the PGA mesh was $50 \mathrm{mg} / \mathrm{cm}^{3}$ and the porosity was approximately $97 \%$. The crystallinity of PGA fiber was $57 \%$, as measured by differential scanning calorimetry. The PGA matrices were cut into squares $(5 \times 5 \mathrm{~mm})$ and prewet in tubes containing $15 \mathrm{~mL}$ of $10 \%(\mathrm{v} / \mathrm{v})$ serum-containing medium. The medium and PGA matrices were mixed at 100 rpm for $24 \mathrm{~h}$ using an orbital shaker (Bellco Glass, Inc.) prior to cell seeding to allow the adsorption of attachment proteins (e.g., fibronectin) contained in the serum onto the PGA fibers.

\section{Seeding Methods}

Three different methods (static, stirred, and agitated) were used to seed SMCs onto PGA matrices. In the static seeding method, $50 \mu \mathrm{L}$ of a cell suspension containing $0.1-2 \times 10^{7}$ cells/mL was injected into polymer matrices in tissue culture dishes. After 4 and $10 \mathrm{~h}, 0.5$ and $1 \mathrm{~mL}$ of culture medium was added to each matrix, respectively. In the stirred seeding method, polymer matrices and cells $(0.2-2 \times$ $10^{6}$ cells $\left./ \mathrm{mL}\right)$ in $40 \mathrm{~mL}$ of growth medium were added to spinner flasks $(100 \mathrm{~mL})$ and stirred at $50 \mathrm{rpm}$ for $20 \mathrm{~h}$. In the agitated seeding method, $0.3 \mathrm{~mL}$ of growth medium containing polymer matrices and cells $\left(0.1-1 \times 10^{7}\right.$ cells $\left./ \mathrm{mL}\right)$ were placed in $50-\mathrm{mL}$ tubes on an orbital shaker (Bellco Glass, Inc.) and agitated at $100 \mathrm{rpm}$ for $20 \mathrm{~h}$. In all methods, seeded matrices were washed with phosphate-buffered saline (PBS, Gibco) after $20 \mathrm{~h}$ of seeding and cultured or used 
for analytical assay. Control studies indicated that cell viability and the ability of cells in the seeding solution to adhere remained high during this period of cell seeding in the various stirring speeds utilized (data not shown). Seeding efficiencies were determined by comparing the number of cells adherent to the matrices to that of cells present in the seeding solution.

\section{Culture of Cell-Polymer Constructs}

PGA matrices seeded with the static (cell concentration in the seeding solution $=5 \times 10^{6}$ cells $/ \mathrm{mL}$ ) or stirred (cell concentration in the seeding solution $=2 \times 10^{6}$ cells $/ \mathrm{mL}$ ) methods were cultured in T flasks $\left(75 \mathrm{~cm}^{2}\right)$ for 4 weeks. For the experiments of the optimization of culture conditions, PGA matrices were seeded with SMCs by the agitated seeding method (cell concentration in the seeding solution $=2$ $\times 10^{7}$ cells $/ \mathrm{mL}$ ). Following cell seeding, cell-polymer constructs were cultured in $\mathrm{T}$ flasks $\left(75 \mathrm{~cm}^{2}\right)$ or spinner flasks (working volume $=50 \mathrm{~mL}$ ) stirred at $40 \mathrm{rpm}$ for 7 weeks in a humidified $5 \% \mathrm{CO}_{2}$ atmosphere and the medium was changed every other day.

\section{Implantation of SMCs}

SMCs were seeded onto PGA matrices using the stirred seeding method (cell concentration in the seeding solution $=2 \times 10^{6}$ cells $/ \mathrm{mL}$ ), cultured in a spinner flask for 2 weeks, and subsequently implanted into subcutaneous pockets in adult male Lewis rats for up to 8 weeks. Each cell-polymer construct was fixed in place by suturing the cell-polymer constructs to the intramuscular layer with a nonabsorbable suture (Prolene 4-0, Ethicon, Inc., Somerville, NJ).

\section{Analytical Assays}

Cells adherent to polymer matrices were fixed with glutaraldehyde (1\%) and stained with osmium tetraoxide $(1 \%)$ for gross visualization of cells in the matrices. For scanning electron microscopic examination, samples were fixed in $1 \%$ glutaraldehyde and $0.1 \%$ formaldehyde for $30 \mathrm{~min}$ and $24 \mathrm{~h}$, respectively, dehydrated with a graded ethanol series, and dried. The dried samples were mounted on aluminum supports and sputter coated with gold. A scanning electron microscope (ISI-DS 130, Topcon Technologies, Pleasanton, CA) was used to image the samples.

The number of cells in the matrices was determined by measuring the amount of DNA in enzyme-digested samples using Hoechst 33258 dye and a fluorometer (Hoefer DyNA Quant 200, Pharmacia Biotech, Uppsala, Sweden) (Kim et al., 1988). For this assay, samples were washed with PBS, lyophilized, and digested in proteinase $\mathrm{K}(0.5 \mathrm{mg} / \mathrm{mL}$ proteinase $\mathrm{K}$ and $0.1 \mathrm{mg} / \mathrm{mL}$ SDS in a buffer solution of $50 \mathrm{mM}$ Tris-HCl, 0.1 $M$ EDTA, $0.2 M \mathrm{NaCl}, \mathrm{pH} 7.4$ ) for $10 \mathrm{~h}$ at $55^{\circ} \mathrm{C}$ with occasional gentle shaking. For measurement, $5-50 \mu \mathrm{L}$ of sample was aliquoted into a cuvette and mixed with $2 \mathrm{~mL}$ of dye solution $(10 \mathrm{~m} M$ Tris, $1 \mathrm{~m} M$ EDTA
$\mathrm{Na}_{2} \cdot 2 \mathrm{H}_{2} \mathrm{O}, 0.2 M \mathrm{NaCl}, 0.1 \mu \mathrm{g} / \mathrm{mL}$ Hoechst 33258 dye). DNA content was calibrated with calf thymus DNA (Pharmacia Biotech) prior to measurement and read using the fluorometer that has an excitation wavelength of $365 \mathrm{~nm}$ and an emission of $460 \mathrm{~nm}$. An SMC contained $7.6 \mathrm{pg}$ DNA, as measured with this method.

For histological analysis, samples were fixed in $10 \%$ (v/ v) buffered formalin, paraffin embedded, sectioned, and stained with hematoxylin and eosin (H\&E) or Verhoeff's staining.

The relative synthesis rates of elastin and collagen were determined using a technique described by Kolpakov et al. (1995). Cell-polymer constructs cultured for 2 weeks were labeled with $3 \mu \mathrm{Ci} / \mathrm{mL}$ of $\mathrm{L}-\left[2,3,4,5-{ }^{3} \mathrm{H}\right]$ proline (DuPont NEN, Boston, MA) in the growth medium. After $24 \mathrm{~h}$ of labeling, the samples were digested with $5 \%(\mathrm{w} / \mathrm{v}) \mathrm{CNBr}$ (Sigma) in $70 \%$ (v/v) formic acid (Sigma) under $\mathrm{N}_{2}$ at $20^{\circ} \mathrm{C}$ for $24 \mathrm{~h}$ to digest all nonelastin proteins, washed with $\mathrm{H}_{2} \mathrm{O}$ 3 times, and dissolved in a tissue solubilizer (Solvable ${ }^{\mathrm{TM}}$, DuPont NEN). Liquid scintillation fluid (EcoLite ${ }^{\mathrm{TM}}$, ICN, Costa Mesa, CA) was then added, and rate of disintegrations per minute (representing the relative rate of elastin synthesis) was measured. To measure the relative rate of collagen synthesis, the growth medium containing L-[2,3,4,5${ }^{3} \mathrm{H}$ ]proline $(3 \mu \mathrm{Ci} / \mathrm{mL})$ and sodium ascorbate $(50 \mu \mathrm{g} / \mathrm{mL}$, Sigma) was added to the culture and incubated for $24 \mathrm{~h}$. Cell-polymer constructs were then separated from the medium fraction. Cold 10\% (w/v) trichloroacetic acid (TCA, Sigma) was added to both cell-polymer constructs and the medium fraction for protein precipitation. Precipitated proteins were collected and digested with a highly specific collagenase (collagenase form III, $10 \mathrm{U} / \mathrm{mL}$, Advance Biofactures Corp., Lynbrook, NY) for $2 \mathrm{~h}$ at $37^{\circ} \mathrm{C}$. The noncollagen proteins were precipitated with $20 \%$ (w/v) TCA, and collected. Liquid scintillation fluid was added and the rate of disintegrations per minute (representing noncollagen synthesis rate) was measured. The relative rate of collagen synthesis was determined, assuming that the ratio of proline residues in collagen relative to noncollagen protein is 5.4 (Kolpakov et al., 1995).

A commercially available assay kit (Fastin elastin assay kit, Accurate Chemical \& Scientific Corp., Westbury, NY) was used to quantitate the elastin. Insoluble elastin in cellpolymer constructs was solubilized by hot oxalic acid treatment, precipitated, and mixed with the Fastin dye reagent. The elastin-dye complex was then collected by centrifugation. The dye bound to the elastin pellet was solubilized with the Destain reagent. The recovered dye concentration was measured at $513 \mathrm{~nm}$.

PGA degradation was determined by measuring the mass change of PGA matrices maintained in $37^{\circ} \mathrm{C}$ PBS under static or stirred conditions. The cell dry mass in the cellpolymer constructs was calculated by multiplying the cell number determined by the DNA assay by the dry mass of an SMC $\left(2.7 \times 10^{-10} \mathrm{~g} /\right.$ cell $)$. 


\section{Statistical Analysis}

All quantitative results were obtained from triplicate samples. Data were expressed as the mean \pm SD. Statistical analysis was carried out using the unpaired Student's $t$ test (InStat ${ }^{\mathrm{TM}}$, GraphPad Software Inc., San Diego, CA). A value of $p<0.05$ was considered to be statistically significant.

\section{RESULTS}

\section{Optimizing Cell Seeding and lts Role in Tissue Development}

PGA fiber based scaffolds were utilized as biodegradable synthetic ECMs in these studies. Three types of SMC seeding onto polymer matrices were first examined to optimize cell seeding. In the static seeding method (Freed et al., 1993), a cell suspension $\left(50 \mu \mathrm{L}, 0.1-2 \times 10^{7}\right.$ cells $\left./ \mathrm{mL}\right)$ was injected into the PGA matrices. However, this method yielded small numbers of cells adherent to the matrices (Fig. 1a), probably due to the low chance of cell contact with PGA fibers in the highly porous matrix (approximately 97\% porous). Most cells likely stayed in the interfiber space and did not contact PGA fibers. Two dynamic seeding methods, stirred and agitated, were next investigated in an effort to increase the number of cells adherent to the polymer matrices. Scanning electron microscopic examination of samples indicated that the stirred or agitated seeding method resulted in a significantly higher number of adherent cells compared to the static seeding method (Fig. 1). Individual cells attached to polymer fibers and cell clusters filling the interconnecting spaces in the polymer matrices could both be visualized when the stirred or agitated seeding method was used. The number of adherent cells as a function of cell concentration in the seeding solution with all three seeding methods was subsequently quantitated using a fluorometric DNA assay. The number of adherent cells per matrix increased with cell concentration in the seeding solution for all the seeding methods, but more cells adhered with the stirred or agitated seeding method than the static method over the entire range of cell concentrations in the seeding solutions (Fig. 2). Gross examination of osmium tetraoxide stained samples revealed a much higher density of cells in dynamically seeded polymer matrices than statically seeded ones, and the cell distribution was more even with these seeding methods as well (not shown). Importantly, while both stirred and agitated seeding methods yielded a large number of adherent cells, the efficiencies of the two methods varied considerably. The seeding efficiency in the stirred method was $4 \pm 1 \%$, while in the agitated method the efficiency was $56 \pm 4 \%$.

Polymer matrices seeded with the static and stirred seeding methods were subsequently maintained in vitro under standard tissue culture conditions (tissue culture flask) for 4 weeks to determine whether the seeding process ultimately regulated the structure of tissue formed by the seeded cells.

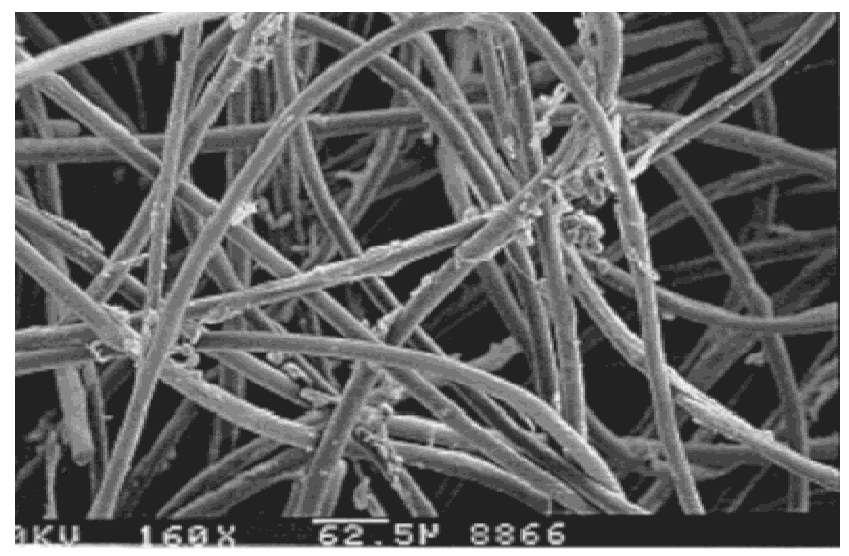

(a)

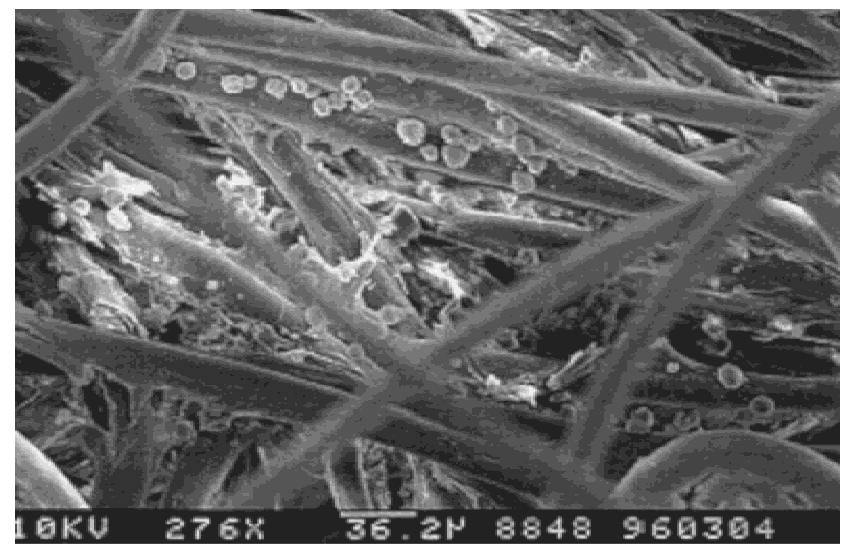

(b)

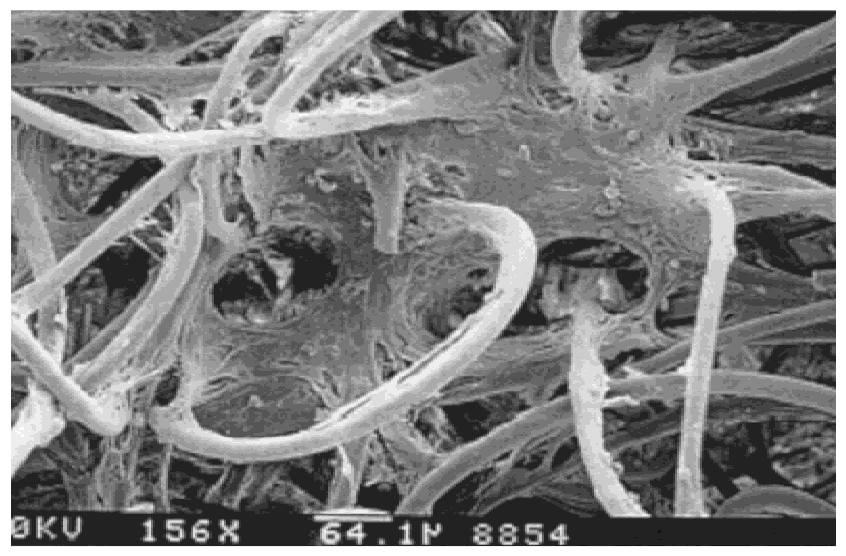

(c)

Figure 1. Scanning electron micrographs of SMCs adherent to PGA fibers after $20 \mathrm{~h}$ of cell seeding: (a) static seeding method (cell concentration in the seeding solution of $2 \times 10^{7}$ cells $/ \mathrm{mL}$ ); (b) stirred seeding method (cell concentration in the seeding solution of $2 \times 10^{6}$ cells $/ \mathrm{mL}$ ); (c) agitated seeding method (cell concentration in the seeding solution of $10^{7}$ cells/ $\mathrm{mL}$ ). Size bars are shown on the photomicrographs.

The SMCs proliferated in culture to fill the void space present between polymer fibers under all conditions, resulting in the generation of new SM tissue (Fig. 3a,b). However, matrices seeded with the stirred seeding method yielded not only more cells adhering to matrices after $20 \mathrm{~h}$ of seeding $\left(7.3 \pm 1.6 \times 10^{4}\right.$ versus $8.5 \pm 0.7 \times 10^{5}$ cells/matrix for the static and stirred seeding method, respectively), but also a 


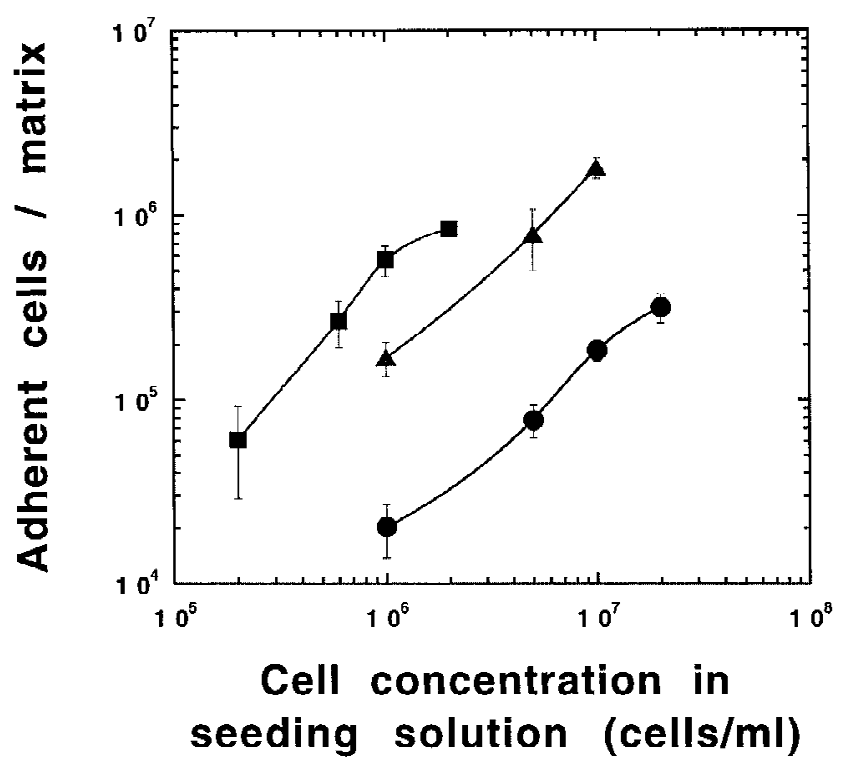

Figure 2. Number of cells adherent to each matrix as a function of cell concentration in the seeding solution after $20 \mathrm{~h}$ of cell seeding with the (-) static, ( $\mathbf{\square})$ stirred, or $(\boldsymbol{\Lambda})$ agitated seeding method. The number of cells per matrix was determined by a fluorometric DNA assay. The difference between the static seeding method and the other two seeding methods was statistically significant $(p<0.05)$ for all cell concentrations in the seeding solution.

significantly increased number of cells in the cell-polymer constructs after 4 weeks of culture than matrices seeded with the static method $\left(1.8 \pm 0.2 \times 10^{6}\right.$ versus $5.3 \pm 1.3 \times$ $10^{6}$ cells/matrix for the static and stirred seeding method, respectively) (Fig. 4). H\&E staining (Fig. 3a,b) indicated that 4-week cell-polymer constructs seeded with the stirred method contained more cells and extracellular proteins than those seeded with the static method. Furthermore, cells and extracellular proteins in cell-polymer constructs seeded with the stirred method were distributed more uniformly throughout the constructs compared to those seeded with the static method. Verhoeff's staining (Fig. 3c,d) showed that the extracellular matrix in 4-week cell-polymer constructs seeded with the stirred method stained more strongly positive for elastin, an extracellular protein that is a major component of SM tissue and largely determines the mechanical properties of SM tissue. PGA fibers exhibited significant erosion by 4 weeks under both conditions.

\section{Optimizing Culture Conditions}

To investigate whether enhanced nutrient transport in the culture system would improve tissue development, polymer matrices seeded with the agitated seeding method were cultured in tissue culture $\mathrm{T}$ flasks (static culture) or in spinner flasks (stirred culture). Static-cultured tissue constructs exhibited an uneven cell distribution and a low cellularity in the center of the constructs after 5 weeks of culture (Fig. 5a). Most cells had preferably grown near the periphery of the construct. In contrast, stirred-cultured cell-polymer con- structs showed a significantly higher cellularity and more uniform cell distribution through the constructs after the same period of culture (Fig. 5b). Quantitation of cell density in these constructs confirmed that the stirred-cultured tissue constructs had a much higher cell density than the staticcultured tissue constructs (Fig. 6). Importantly, the stirredcultured constructs had a cell density of $6.4 \pm 0.8 \times 10^{8}$ cells $/ \mathrm{cm}^{3}$ after 5 weeks, which is comparable to native SM tissue (Kleinert et al., 1996).

The production and accumulation of extracellular proteins in the engineered SM tissue were also examined in respect to the culture conditions. The rate of elastin synthesis in tissue constructs cultured in the stirred bioreactors, measured with the use of radioactive proline, was increased by $11 \%$ relative to that of the static-cultured constructs (Table I). Histological examination of the tissue constructs stained for elastin (Verhoeff's staining) indicated that significantly more elastin was accumulated over 5 weeks when constructs were cultured under stirred versus static conditions (Fig. 5c,d). Similarly, the rate of collagen synthesis in the stirred cultured constructs was increased by $20 \%$ compared to static conditions (Table I).

The overall compositions of engineered SM tissues were next compared for constructs cultured under stirred or static conditions (Fig. 7). The engineered SM tissue constructs consisted of PGA, SMCs, and extracellular proteins. The dry mass percentages of cells and elastin increased while that of PGA decreased as a function of culture time. However, tissue developed in stirred bioreactors contained higher densities of cells and ECM proteins compared to static-cultured tissue. For example, the tissue constructs cultured under stirred conditions consisted of $37 \pm 4 \%$ of cells after 7 weeks of culture, while cells in the static-cultured tissue constructs accounted for $21 \pm 4 \%$ of the total dry mass of the new tissue. In addition, the elastin content was $24 \pm 3 \%$ after 5 weeks of stirred culture, while it was only $14 \pm 3 \%$ after 5 weeks of static culture. Importantly, the elastin content of stirred-cultured tissue constructs was similar to that of native SM tissue (Simionescu and Simionescu, 1988). The collagen contents in the tissue constructs were less than 5\% in both cases, but stirred tissues contained an average of $27 \%$ more collagen than static cultured tissues.

\section{Tissue Formation In Vivo}

SMCs seeded on biodegradable polymer matrices were implanted subcutaneously to determine if tissues engineered in vitro could be utilized to create new tissues in vivo. Preliminary results indicated SMCs throughout the devices 18 days after implantation (Fig. 8), and the highest density of cells was located on the periphery. A number of capillaries were found around the periphery of the polymer matrices (not shown), and the PGA fibers were clearly visible throughout the explanted tissue constructs. At later times, samples demonstrated PGA degradation, a higher level of 


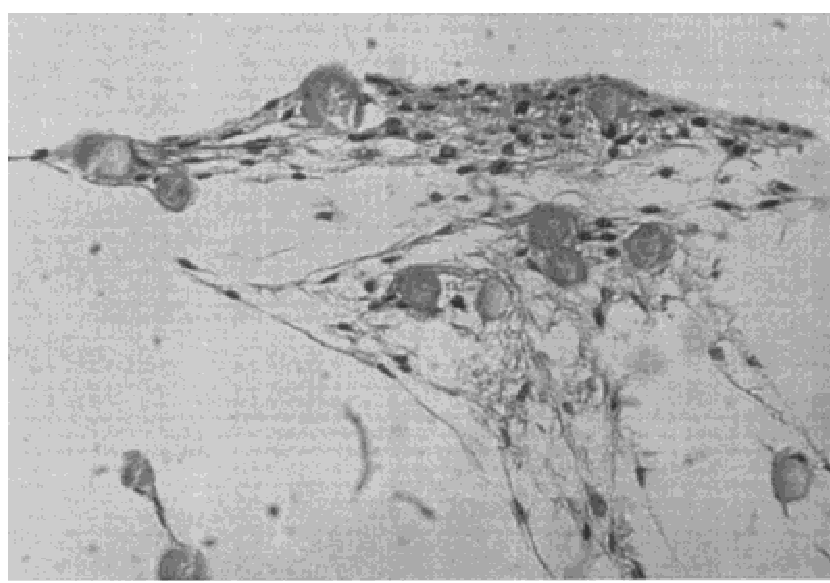

(a)

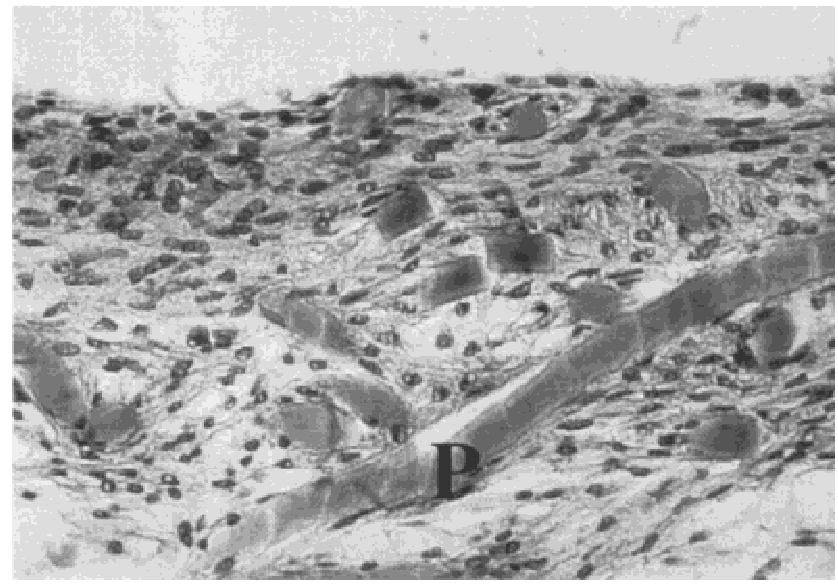

(b)

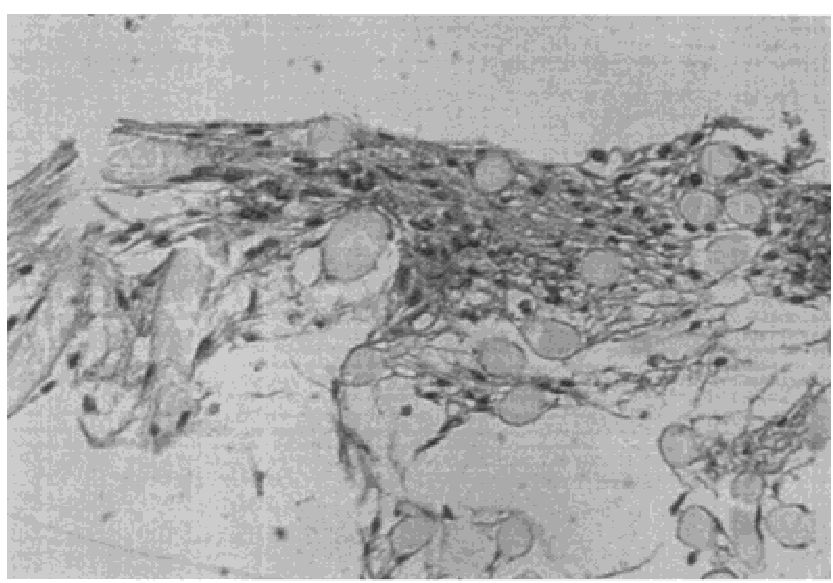

(c)

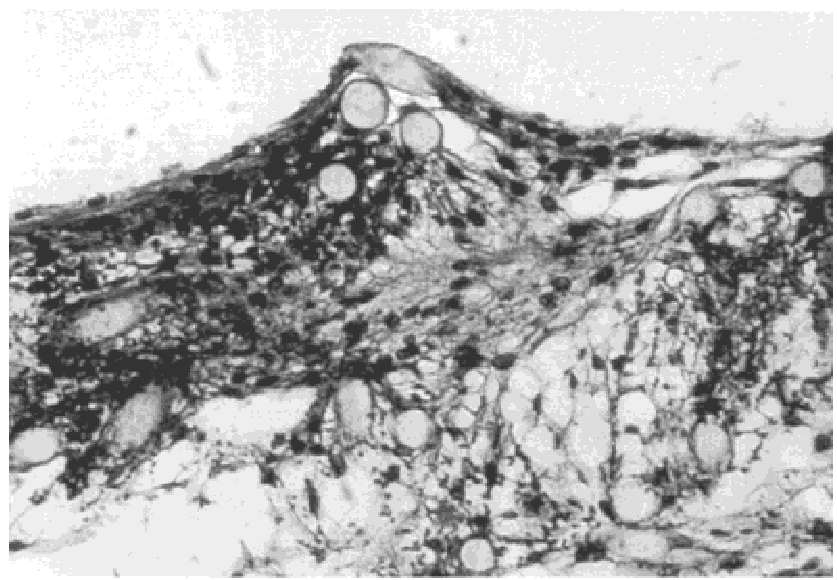

(d)

Figure 3. Cross sections of engineered tissues stained with $(a, b) H \& E$ or $(c, d)$ Verhoeff's after 4-week static culture. Matrices were seeded with (a,c) the static seeding method $\left(5 \times 10^{6}\right.$ cells $\left./ \mathrm{mL}\right)$ or $(\mathrm{b}, \mathrm{d})$ the stirred seeding method $\left(2 \times 10^{6}\right.$ cells $\left./ \mathrm{mL}\right)$. Polymer fibers $(\mathrm{P})$ are visible. The original magnification of these photomicrographs was $\times 400$.

vascularization, and increased overall cellularity (not shown).

\section{DISCUSSION}

Biodegradable polymer matrices are attractive synthetic ECMs for tissue engineering and cell transplantation because they act as a temporary matrix and resorb while a new tissue develops from seeded cells. This study shows that a SM tissue comparable in many respects to native SM tissue can be engineered by optimizing cell seeding and culture conditions on PGA fiber based matrices.

The cell seeding method was determined to be a critical determinant not only of the density of cells initially adherent to the polymer matrices, but also of the quality of the tissues that developed over time from the cell seeded matrices. Seeding highly porous polymer matrices with the static seeding method yielded few cells adherent to PGA fibers. The matrices utilized in this study had an average interfiber spacing of $200 \mu \mathrm{m}$ and a porosity of $97 \%$. Most cells seeded into these matrices with the static seeding method likely did

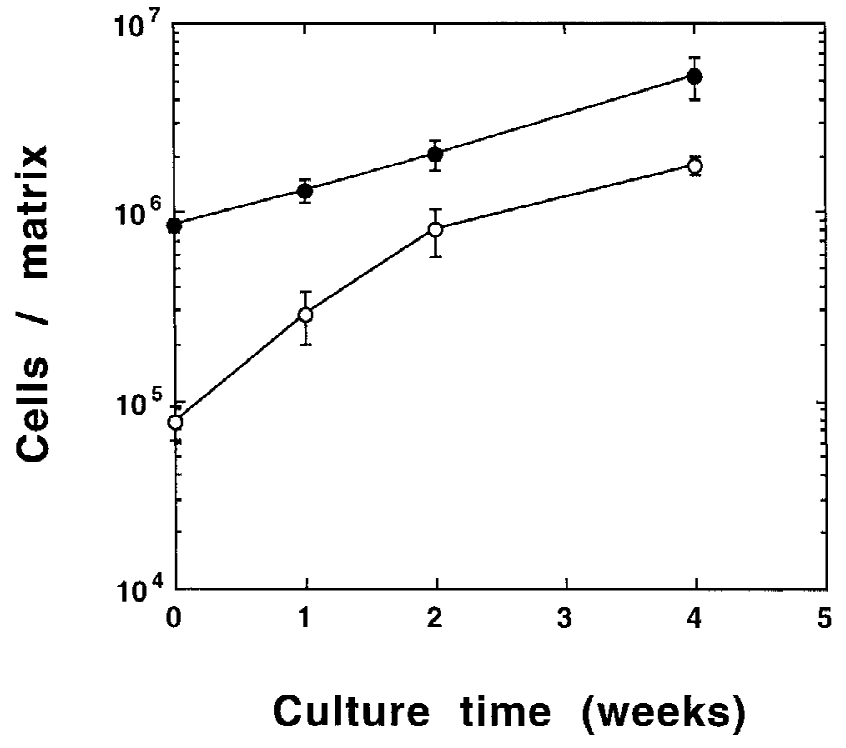

Figure 4. Number of cells over time in statically cultured cell-polymer constructs seeded with $(O)$ the static seeding method $\left(5 \times 10^{6}\right.$ cells $\left./ \mathrm{mL}\right)$ or (-) the stirred seeding method $\left(2 \times 10^{6}\right.$ cells $\left./ \mathrm{mL}\right)$. The difference between the cell densities at the two conditions was statistically significant $(p<$ $0.01)$ at all time points. 


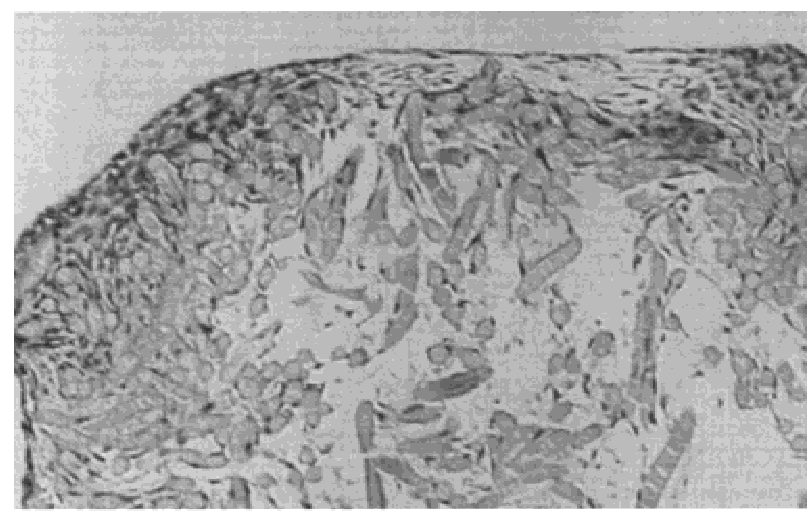

(a)

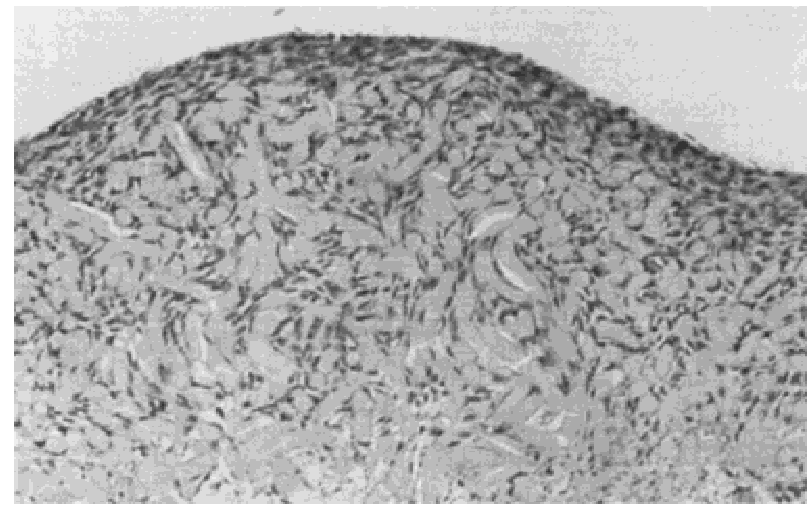

(b)

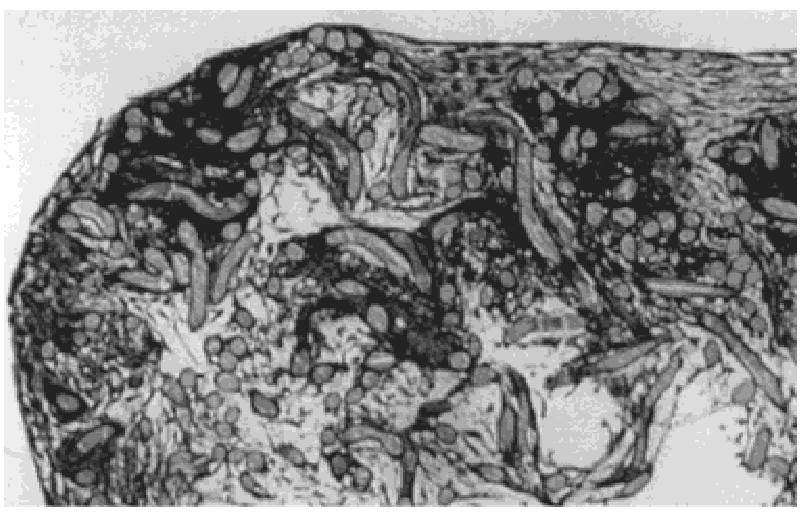

(c)

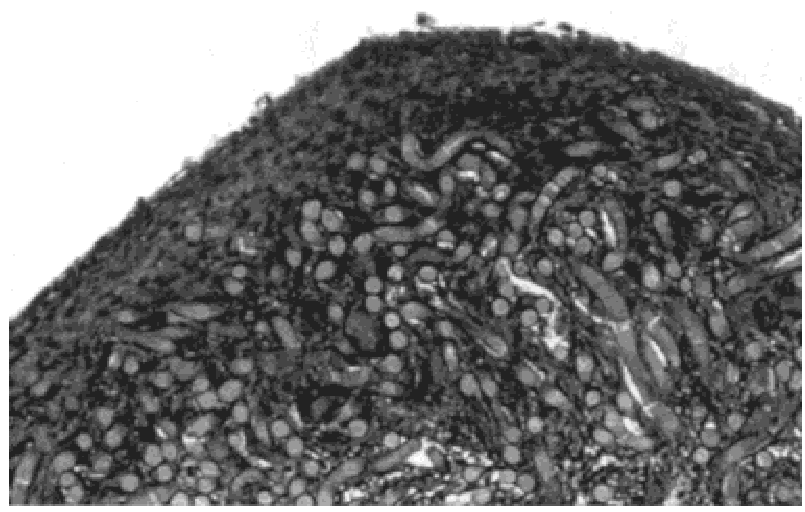

(d)

Figure 5. Cross sections of engineered tissues stained with (a,b) H\&E or (c,d) Verhoeff's cultured for 5 weeks $(a, c)$ under static conditions or (b,d) in a stirred bioreactor. The original magnification of these photomicrographs was $\times 200$.

not have a sufficient number of interactions with the polymer fibers to adhere. In contrast, the dynamic seeding methods typically resulted in at least an order of magnitude higher density of SMCs adherent to polymer matrices, and a more even cell distribution in the matrices. Presumably

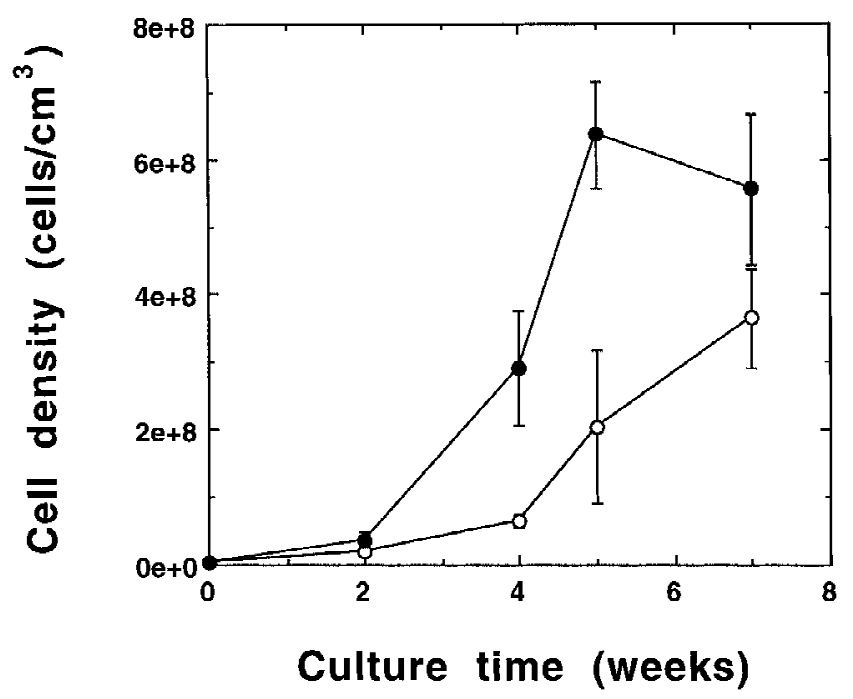

Figure 6. The cell density of tissues cultured under $(\bigcirc)$ static or ( stirred conditions over time. this results from increasing the number of collisions between cells and PGA fibers as the cell suspension is repeatedly passed through the polymer matrix by stirring or agitating. Although both the stirred and agitated seeding methods resulted in high seeding densities, the seeding efficiency in the stirred method $(4 \pm 1 \%)$ was considerably lower than that in the agitated $(56 \pm 4 \%)$. The volumes of seeding solution used in the stirred and agitated seeding methods were 40 and $0.3 \mathrm{~mL}$, respectively. These results provide a starting point for further optimization of bioreactors for cell seeding and culture. The bioreactor should not only render a high number of collisions between cells and polymer matrices, but also have a small cell suspension volume to increase cell seeding efficiency.

The culture conditions utilized subsequent to cell seeding were critical to the long-term cellularity and ECM protein content of the engineered tissues. Static culture of dynami-

Table I. Relative synthesis rate of elastin and collagen of static- or stirred-cultured SMC-polymer constructs.

\begin{tabular}{lcc}
\hline Relative rate measured & Static culture & Stirred culture \\
\hline Elastin synthesis & $1.00 \pm 0.06$ & $1.11 \pm 0.15$ \\
Collagen synthesis $^{\mathrm{a}}$ & $1.00 \pm 0.04$ & $1.20 \pm 0.11$ \\
\hline
\end{tabular}

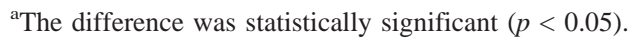




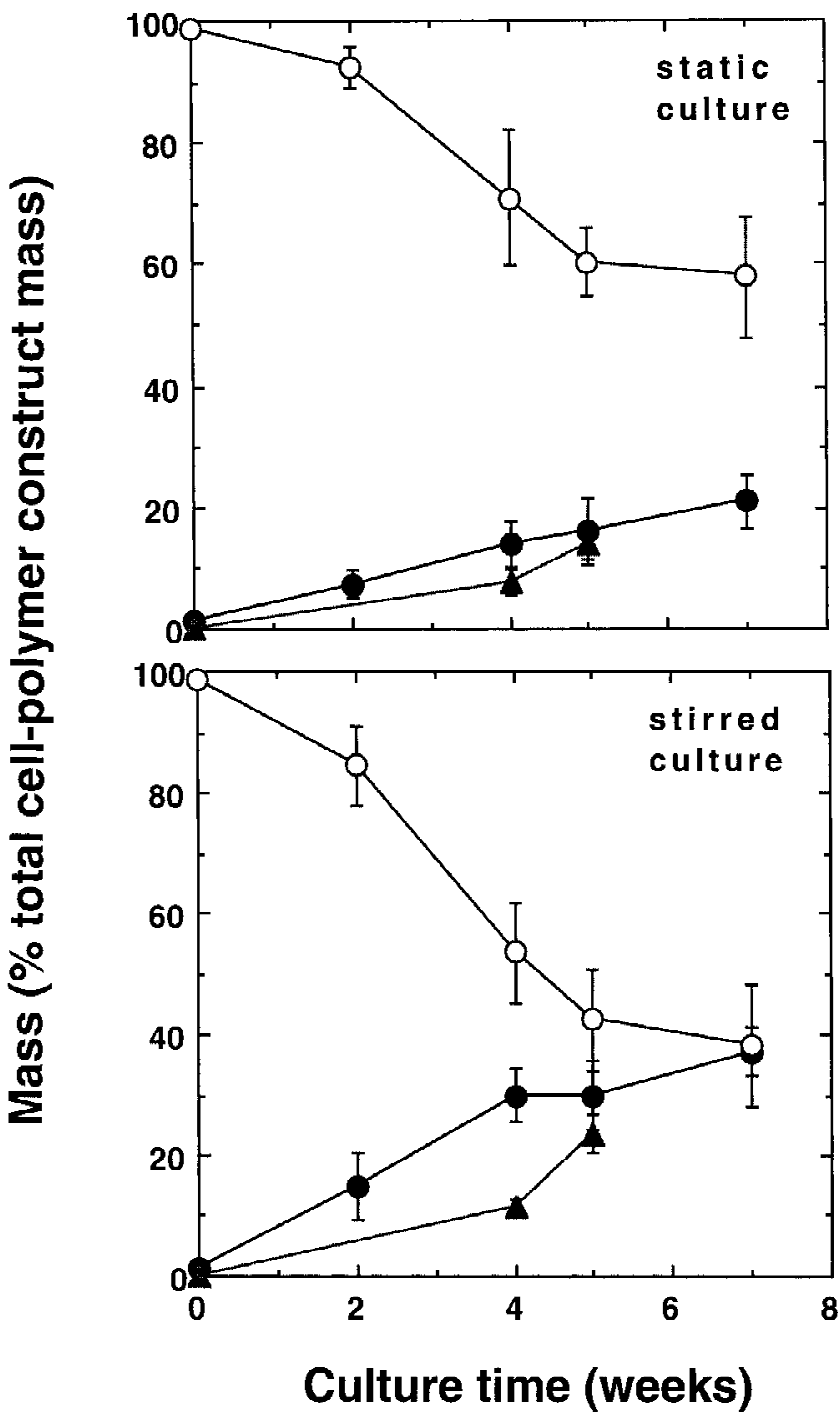

Figure 7. The composition of engineered SM tissues cultured under static or stirred conditions. The tissues mainly consist of $(\bigcirc)$ PGA, ( $)$ cells, and $(\mathbf{A})$ elastin. The results were normalized to the total dry weight of the tissues at each time point.

cally seeded matrices resulted in a low cellularity in the center of the tissue constructs and an uneven cell distribution. Nutrients transport into the constructs by diffusion under this condition, and this likely resulted in a gradient of nutrients from the exterior to the interior of the matrices. Cells in the interior of the matrices likely grew slower than those on the surface of the matrices, and this enhanced the lower cellularity and less even cell distribution in the staticcultured tissue constructs than in the stirred-cultured tissue constructs. The poor tissue development by a static culture was improved by culture in a stirred bioreactor, likely due to the enhancement in nutrient transport. Cells grew more uniformly throughout the constructs in stirred bioreactors, resulting in a new tissue with a high cellularity and more uniform cell distribution. This culture condition also resulted in an increase of synthesis and deposition of the ECM proteins, elastin, and collagen. This is a critical finding be- cause collagen and elastin are largely responsible for the mechanical properties of SM tissue.

In past studies, naturally derived materials have been commonly utilized as matrices to guide SM tissue development (Dickinson et al., 1994; Hirai and Matsuda, 1995; Weinberg and Bell, 1986; Ziegler and Nerem, 1994). The resulting SM tissues typically have a very low cell density [e.g., $10^{7}$ cells $/ \mathrm{cm}^{3}$ when type I collagen gels were utilized (Ziegler and Nerem, 1994)] that is far below that found in the present study and in vivo. In addition, tissues containing a high percentage of elastin, which is a major ECM protein in SM tissue, have not been previously obtained with other experimental systems. The synthetic polymer matrices utilized in the present study can also be easily and reproducibly processed to yield matrices with controlled mechanical properties and degradation rates (Mooney et al., 1996). Another study with these types of matrices also demonstrated that dynamic cell seeding and culture conditions enhance the formation of cartilaginous tissues from seeded chondrocytes (Freed et al., 1994). However, relatively small increases in cellularity (approximately 25\%) were found in dynamic versus stirred conditions in that study. It is likely that enhancement of mass transport is more critical for SM tissue than for cartilage, which has a very low metabolic rate.

In the present study we demonstrated that PGA matrices can be used to engineer tissues with comparable cell density and elastin content to those found in vivo, but neither the cells nor ECM proteins were organized in vitro as they are in native SM tissue. We propose that mechanical forces (e.g., cyclic tensile loading) exerted on these tissues in vivo play an important role in cell and ECM protein organization. Previous investigations have shown that mechanical stimulation of SMCs in 2-dimensional and 3-dimensional culture influences ECM production (Kolpakov et al., 1995; Leung et al., 1976) as well as cell morphology (Dartsch et al., 1986) and proliferation (Birukov et al., 1995; Kolpakov et al., 1995). A recent study of SM transplantation has dem-

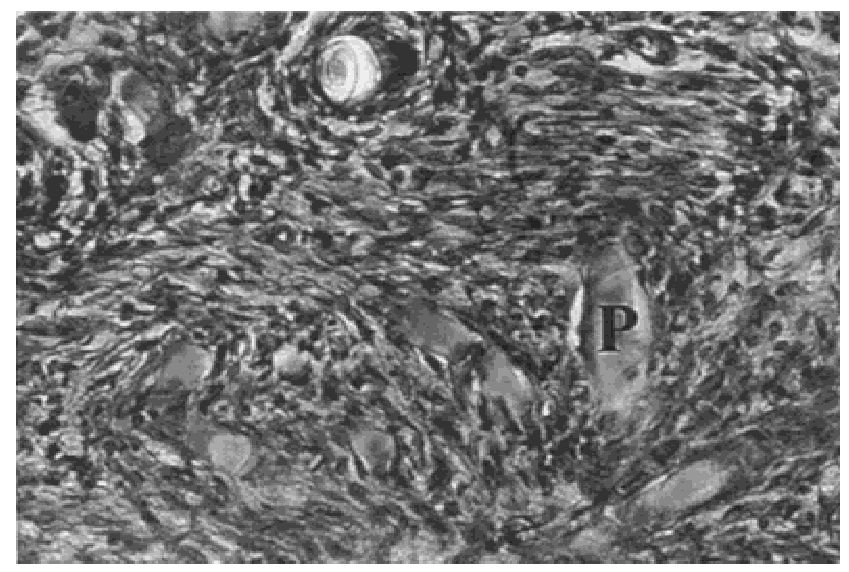

Figure 8. H\&E stained cross section of new tissue 18 days in vivo. Matrices were seeded and cultured for 14 days before implantation. Polymer fibers $(\mathrm{P})$ are visible in the photomicrograph along with the new tissue. The original magnification of the photomicrograph was $\times 400$. 
onstrated alignment of SMCs and ECM when implanted as a venous substitute (Hirai and Matsuda, 1996). It is not clear if this reorganization was due to the environment of the implant or the long-term implantation (24 weeks in this study). At this time we are investigating the role of mechanical stimulation on the development of SM tissue in the experimental system described in this report.

We demonstrated that an optimized experimental system can lead to the development of SM tissue with cellular and biochemical characteristics comparable in some aspects to native SM. The model may be valuable in studies of SM tissue development in which variables such as cell-cell interactions, soluble factors, and mechanical signals can be readily varied. The knowledge obtained from such model systems may ultimately lead to new clinical therapies (engineered tissues) for the large number of diseases compromising the function of tissues containing SM. Engineered tissues may provide the ultimate therapy for these diseases, and the model system described in this report may significantly improve and hasten the development of these tissues. Additionally, this model system may lead to an improved understanding of molecular mechanisms in vascular biology and pathology (e.g., atherosclerosis and restenosis).

This work was supported by the National Science Foundation (BES-9501376). The authors thank Helena Hennighausen and Andrea Brown for technical assistance.

\section{References}

Atala, A., Freeman, M. R., Vacanti, J. P., Shepard, J., Retik, A. 1993 Implantation in vivo and retrieval of artificial structures consisting of rabbit and human urothelium and human bladder muscle. J. Urol. 150: 608-612.

Birukov, K. G., Shirinsky, V. P., Strpaanova, O. V., Tkachuk, V. A., Hahn, A. W. A., Resink, T. J., Smirnov, V. N. 1995. Stretch affects phenotype and proliferation of vascular smooth muscle cells. Mol. Cell. Biochem. 144: 131-139.

Dartsch, P. C., Hämmerle, H., Betz, E. 1986. Orientation of cultured arterial smooth muscle cells growing on cyclically stretched substrates. Acta Anat. 125: 108-113.

Dickinson, R. B., Guido, S., Tranquillo, R. 1994. Biased cell migration of fibroblasts exhibiting contact guidance in oriented collagen gels. Ann. Biomed. Eng. 22: 342-356.

Freed, L. E., Marquis, J. C., Nohia, A., Emmanual, J., Mikos, A. G., Langer, R. 1993. Neocartilage formation in vitro and in vivo using cells cultured on synthetic biodegradable polymers. J. Biomed. Mater. Res. 27: 11-23.
Freed, L. E., Marquis, J. C., Vunjak-Novakovic, G., Emmanual, J., Langer, R. 1994. Composition of cell-polymer cartilage implants. Biotechnol. Bioeng. 43: 605-614.

Gilding, D. K. 1981. Biodegradable polymers, pp. 209-232. In: D. F. Williams (ed.), Biocompatibility of clinical implant materials. CRC Press, Boca Raton, FL.

Greisler, H. P. 1991. New biologic and synthetic vascular prostheses. R. G. Landes Company, Austin, TX.

Hirai, J., Matsuda, T. 1995. Self-organized, tubular hybrid vascular tissue composed of vascular cells and collagen for low-pressure-loaded venous system. Cell Transplant. 4: 597-608.

Hirai, J., Matsuda, T. 1996. Venous reconstruction using hybrid vascular tissue composed of vascular cells and collagen: Tissue regeneration process. Cell Transplant 5: 93-105.

Holmes, S. A. V., Kirby, R. S. 1993. Biomaterials in reconstructive urology: The complications of urogenital prostheses related to their construction, pp. 183-188. In: G. Webster, R. S. Kirby, L. King, and B. Goldwasser (eds.), Reconstructive urology. Blackwell Scientific Publications, Boston.

Kim, Y.-J., Sah, R. L. Y., Doong, J.-Y. H., Grodzinsky, A. J. 1988. Fluorometric assay of DNA in cartilage explants using Hoechst 33258. Anal. Biochem. 174: 168-176.

Kleinert, L. B., Hoying, J. B., Williams, S. K. 1996. The neointima formed in endothelial cell seeded ePTFE vascular grafts results from both cellular-hyperplasia and extracellular-hypertrophy. Cell Transplant. 5: 475-482.

Kolpakov, V., Rekhter, M. D., Gordon, D., Wang, W. H., Kulik, T. J. 1995. Effect of mechanical forces on growth and matrix protein synthesis in the in vitro pulmonary artery. Circ. Res. 77: 823-831.

Langer, R., Vacanti, J. P. 1993. Tissue engineering. Science 260: 920-926.

Leung, D. Y. M., Glagov, S., Mathews, M. B. 1976. Cyclic stretching stimulates synthesis of matrix components by arterial smooth muscle cells in vitro. Science 191: 475-477.

Mooney, D. J., Mazzoni, C. L., Breuer, C., McNamara, K., Hern, D., Vacanti, J. P., Langer, R. 1996. Stabilized polyglycolic acid fibre-based tubes for tissue engineering. Biomaterials 17: 115-124.

Putnam, A. J., Mooney, D. J. 1996. Tissue engineering using synthetic extracellular matrices. Nature Med. 2: 824-826.

Rothman, A., Kulik, T. J., Taubman, M. B., Berk, B. C., Smith, C. W. J., Nadal-Ginard, B. 1992. Development and characterization of a cloned rat pulmonary arterial smooth muscle cell line that maintains differentiated properties through multiple subcultures. Circulation 86: 1977-1986.

Simionescu, N., Simionescu, M. 1988. The cardiovascular system, pp. 353-400. In: L. Weiss (ed.), Cell and tissue biology, 6th edition. Urban \& Schwarzenberg, Baltimore, MD.

Weinberg, C. B., Bell, E. 1986. A blood vessel model constructed from collagen and cultured vascular cells. Science 231: 397-400.

Ziegler, T., Nerem, R. M. 1994. Tissue engineering a blood vessel: Regulation of vascular biology by mechanical stresses. J. Cell. Biochem. 56: 204-209. 